Licença CC BY: Artigo distribuído

sob os termos

Creative Commons, permite uso e distribuição irrestrita em qualquer meio desde que o autor credite a fonte original.

\title{
A HOSPITALIDADE E A INFLUÊNCIA DO ATENDIMENTO NA PERCEPÇÃO DE SATISFAÇÃO DOS HÓSPEDES EM HOTÉIS DE LUXO NO BRASIL
}

\author{
HOSPITALITY AND THE INFLUENCE OF SERVICE IN THE \\ PERCEPTION OF GUEST SATISFACTION IN LUXURY HOTELS IN \\ BRAZIL
}

\begin{abstract}
LA HOSPITALIDAD Y LA INFLUENCIA DE LA ATENCIÓN EN LA PERCEPCIÓN DE SATISFACCIÓN DE LOS HOSTALES EN HOTELES DE LUJO EN BRASIL
\end{abstract}

MARIA STELA REIS CROTTI

UNIVERSIDADE ANHEMBI MORUMBI, SÃO PAULO, SÃO PAULO, BRASIL

SÉRGIO LUIZ DO AMARAL MORETTI²

UNIVERSIDADE FEDERAL DE UBERLÂNDIA, UBERLÂNDIA, MINAS GERAIS, BRASIL

DATA DE SUBMISSÃO: 24/04/2018 - DATA DE ACEITE: 31/05/2019

RESUMO: A hotelaria de luxo está relacionada à diferenciação, à ostentação e às experiências raras. No Brasil, a avaliação e a classificação hoteleira baseiam-se em dois importantes pilares: instalações e serviços. Essa combinação pode criar uma diferenciação no posicionamento de alguns hotéis. A despeito de sua importância, existe uma grande lacuna de conhecimento neste campo, evidenciada pela ausência de estudos acadêmicos, principalmente relacionando a hospitalidade e a hotelaria de luxo no Brasil. Este artigo pretendeu analisar em que medida os conceitos de hospitalidade influenciam o atendimento de hotéis de luxo e verificar se afetam a satisfação dos usuários. Os procedimentos conciliaram os pressupostos para uma pesquisa descritiva com abordagens qualitativas e quantitativas. Os dados foram coletados junto a uma amostra de 462 hóspedes de um mailing list que incluía 25 hotéis de luxo classificados pelo TripAdvisor. Os resultados obtidos por meio do software SmartPLS 3 permitiram identificar que existem relações positivas entre Hospitalidade, Atendimento Diferenciado e Satisfação, não refutando as hipóteses propostas. Reforçou-se a premissa de que o momento do encontro no setor de serviços, principalmente o hoteleiro de luxo, é o principal fator que se deve colocar atenção nesta área, constituindo-se de uma contribuição tanto para a academia quanto para o campo gerencial. Esta pesquisa pode trazer para os gestores do setor hoteleiro insumo para que se construam estratégias associadas a práticas hoteleiras que visem à satisfação de seus hóspedes de acordo com suas expectativas.

\footnotetext{
1 Mestre em Hospitalidade pela Universidade Anhembi Morumbi - SP. E-mail: mcrotti3@gmail.com. Orcid: 0000-0003-3965-3212.

2 Pós-doutor em Marketing e Sustentabilidade pela FEA-USP. Doutor em C. Sociais pela PUC-SP. E-mail: sergiomoretti@uol.com.br. Orcid: 0000-0002-9457-6064.
} 
Rev.Tur., Visão e Ação, v21, n3, p309-335, Set./Dez. 2019 - Balneário Camboriú, Santa Catarina, Brasil

PALAVRAS-CHAVE: Hospitalidade. Mercado de luxo. Indústria hoteleira.

ABSTRACT: The luxury hotel industry is related to differentiated costumer services, ostentation and unique experiences. In Brazil, the evaluation and classification of the hotel industry are based on two important cornerstones: facilities and services. This combination may bring a differentiation for the market positioning of some hotels. Despite the importance of this subject, there is a huge gap in knowledge in academic studies, specially concerning aspects of the Hospitality and hotel industry in Brasil. The main objective of this article is to assess how far the concept of hospitality influences customer services in the luxury hotel market, and whether these concepts affect customer satisfaction. The research procedures included descriptive research with quantitative and qualitative approaches. Data were collected through a survey involving 462 hotel guests and a mailing list of 25 luxury hotels classified on TripAdvisor. The results of the statistical analysis, conducted using the software SmartPLS 3, showed the existence of positive and strong relations between hospitality, customer services and customer satisfaction, corroborating the proposed hypotheses. Thus, the premise was supported that the moment of service, especially in the luxury hotel industry, is an important factor to be considered, and makes a valuable contribution to the management and academic fields. This research may contribute with information for luxury hotel managers that could help them improve their strategies in relation to daily practices, in order to fulfill customers' expectations.

KEYWORDS: Hospitality. Luxury Market. Hotel Industry.

RESUMEN: La hotelería de lujo está relacionada a la diferenciación, a la ostentación y a las raras experiencias. En Brasil, la evaluación y la clasificación hotelera se basan en dos importantes pilares: instalaciones y servicios. Esa combinación puede crear una diferenciación en la posición de algunos hoteles. Con relación a su importancia, existe un gran vacío de conocimiento en este campo, evidenciada por la ausencia de estudios académicos, principalmente relacionándolos a la hospitalidad y a la hotelería de lujo en Brasil. Este artículo pretendió analizar en qué medida los conceptos de hospitalidad influencian la atención de hoteles de lujo y verificar si afectan a la satisfacción de los usuarios. Los procedimientos conciliaron las suposiciones para una investigación descriptiva con abordajes cualitativos y cuantitativos. Los datos fueron colectados junto a una muestra de 462 huéspedes de un mailing list que incluía 25 hoteles de lujo clasificados por TripAdvisor. Los resultados obtenidos por medio del software SmartPLS 3 permitieron identificar que existen relaciones positivas entre Hospitalidad, Atención Especial y Satisfacción, no refutando las hipótesis propuestas. Se reforzó la premisa de que el momento del encuentro en el sector de servicios, principalmente el hotelero de lujo es el principal factor que se debe colocar en atención en esta área, constituyéndose de una contribución tanto para la academia como para el campo gerencial. Esta investigación puede traer para los gestores del sector hotelero insumo para que se construyan estrategias asociadas a prácticas hoteleras que visen a la satisfacción de sus huéspedes de acuerdo con sus expectativas.

PALABRAS-CLAVE: Hospitalidad. Mercado de lujo. Industria hotelera.

\section{INTRODUÇÃO}

O universo do mercado de luxo traz em seu sistema sofisticados tipos de relações entre indivíduos que se distinguem por interesses e valores diferenciados. Nesse setor, a diferenciação e a busca por uma relação que está além das 
premissas do alimentar, entreter e acolher são os elementos que determinam a longevidade da conexão entre o hóspede e seu hospedeiro. A experiência diferenciada que se desencadeia nessa relação procura atender continuamente esses valores, seja pelas instalações, serviços ou, simplesmente, pelo acolhimento.

Em geral, hóspedes e consumidores com poder econômico que lhes permite estar em qualquer hotel no mundo, com os mais diferenciados e personalizados serviços, hospedam-se no mesmo hotel por anos, pois consideram que esse é o lugar do seu lazer, do seu descanso e do seu conforto e, muitas vezes, o de sua família. A hospitalidade, o luxo em si, o status que esse produto agrega a sua forma de vida são elementos importantes na relação desse consumidor com o produto ou o serviço que está sendo consumido. Um hotel de luxo pode trazer em sua rotina diferenciais no atendimento ou no acolhimento a esse nicho de mercado.

Os diferenciais podem ser evidenciados por estratégias e práticas diárias que considerem a participação das equipes, a estruturação dos espaços físicos ou mesmo um olhar atento às expectativas de seus hóspedes. Nesse sentido, identificar os fatores que influenciam a qualidade do atendimento na satisfação do hóspede da hotelaria de luxo torna-se essencial para um posicionamento de mercado diferenciado (Lai \& Hitchcock, 2017). Keating e Harrington (2003) sugerem que o gerenciamento de qualidade nas organizações hoteleiras está carente de envolvimento, comunicação e trabalho em equipe. Mohsin (2010) destaca que a diferença entre os serviços de alta e baixa qualidade está no grau de existência da efetiva participação humana na relação de serviço.

O comportamento de um consumidor pode ser pautado por variáveis que estão presentes em sua essência como ser humano. Para Strehlau (2008), há muitas tensões que habitam o ser humano, sejam elas o ser, o querer, o poder, o saber, o fazer e o ter e todas elas se interligam quando se trata da motivação do luxo. Observa-se a existência de muitos fatores que impulsionam o consumidor de produtos e serviços de luxo e, da mesma maneira, inúmeras perspectivas de como analisá-lo e compreendê-lo.

Neste sentido, Hemetsberger, Wallpach e Baver (2012) observam que o consumo no mercado de luxo não se relaciona mais com o fato de pertencer a determinada classe social, e sim com o fato de esse consumidor desejar experiências que definam sua essência e o significado de seu prazer. Os autores destacam que o significado de consumo de artigos de luxo está baseado na medida da percepção do que é luxo, no valor individual da marca de luxo para cada consumidor e nas práticas individuais de consumo.

A experiência do usuário de hotéis de luxo, proporcionando um significado e um prazer para esse indivíduo, pode encontrar na hospitalidade a essência de seu conceito. Segunda as palavras de Montandon (2011, p. 31), "a hospitalidade não se reduz ao simples oferecimento de um repasto e de um abrigo livremente consentidos: a relação interpessoal instaurada implica uma relação, um vínculo social, valores de solidariedade e de sociabilidade". Para Montandon (2011) e 
Rev.Tur., Visão e Ação, v21, n3, p309-335, Set./Dez. 2019 - Balneário Camboriú, Santa Catarina, Brasil

Camargo (2015), a relação interpessoal destaca-se como o cerne da hospitalidade.

Ao se tratar de hotelaria de luxo no Brasil, depara-se com algumas variáveis que, de certa maneira, dificultaram a categorização de alguns aspectos presentes nesta pesquisa. Uma variável importante foi a da classificação da hotelaria de luxo. No Brasil, a hotelaria de luxo é recente, com sua abertura para o mercado internacional no final dos anos 90 , principalmente com a conscientização de seu mercado para os aspectos apresentados até este momento do estudo. Assim, se considerada a classificação do Ministério do Turismo, os hotéis são categorizados entre uma e cinco estrelas, com base em requisitos mandatórios e eletivos para as condições de infraestrutura, serviços e sustentabilidade. Nesse sentido, os hotéis que são classificados com uma estrela atendem, basicamente, os parâmetros estabelecidos e os que recebem cinco estrelas atendem excedendo todos os requisitos. Essa classificação não foi suficiente para essa pesquisa, o que levou a buscar uma referência a partir da percepção dos consumidores do mercado hoteleiro de luxo. A falta de uma categorização oficial de hotéis de luxo faz com que as classificações e as fontes de informações sejam muito restritas e nem sempre constantes e atualizadas.

Esse aspecto traz um desafio para os gestores dos hotéis classificados como de luxo, sendo essa classificação feita principalmente pela percepção de satisfação ou de atendimento das expectativas de um mercado restrito como é o de luxo. Esse artigo apresentará algumas informações sobre essa referência de qualidade e expectativa presentes para o consumidor do mercado de luxo, propiciando aos gestores desse setor uma referência a partir da percepção desse mercado.

Deve-se destacar também que, a partir dos levantamentos realizados sobre o conceito luxo, muitas foram as facetas encontradas para conceituálo. Contemplar algumas definições de luxo pode auxiliar na compreensão do polissêmico conceito, conforme apresenta Campanário (2014) em seu estudo sobre valor percebido no luxo, destacando definições que foram se alterando no decorrer dos anos. O luxo já teve seu conceito atrelado a preço e qualidade, a status e posição social, e a valor subjetivo percebido pelo consumidor. Segundo Gurzki \& Woisetschläger (2017), as pesquisas sobre a temática luxo evoluíram das tradicionais pesquisas sociológicas para as áreas de gestão, considerando inclusive aspectos de gerenciamento de marca e de falsificação, além de considerar uma nova perspectiva sobre o consumo de luxo, a evolucionista.

O objetivo principal deste artigo é analisar em que medida a hospitalidade influencia o atendimento de hotéis de luxo e verificar se essa relação afeta a satisfação dos usuários. Com base nessa questão, pretende-se averiguar o nível de hospitalidade percebido pelos usuários dos hotéis de luxo e sua satisfação em relação aos conceitos da hospitalidade, além do atendimento em relação aos serviços diferenciados apresentados e a experiência do hóspede como única e distinta. Este artigo está estruturado de forma a apresentar uma revisão da literatura sobre o tema, os procedimentos metodológicos da pesquisa realizada, 


\section{TURISM禺}

uma análise e discussão dos principais resultados e as conclusões finais.

\section{FUNDAMENTAÇÃO TEÓRICA}

\section{A Hospitalidade}

A hospitalidade trata-se de um signo de civilização, que ocorre entre o anfitrião ou provedor de serviços e o hóspede ou cliente que recebe este serviço, analisada, segundo Lashley (2000), sob a perspectiva de três domínios: social, privado e comercial. Na perspectiva doméstica ou privada, a hospitalidade está em alimentar e hospedar, sempre relacionada com as obrigações do hóspede e do anfitrião. No aspecto social, consideram-se todas as interações culturais e sociais na relação estabelecida entre eles, demonstradas na figura a seguir.

Na Figura 1, Lashley (2000) destaca os três contextos e localiza a experiência da hospitalidade na intersecção dos três aspectos.

Figura 1 - Os três contextos da Hospitalidade.

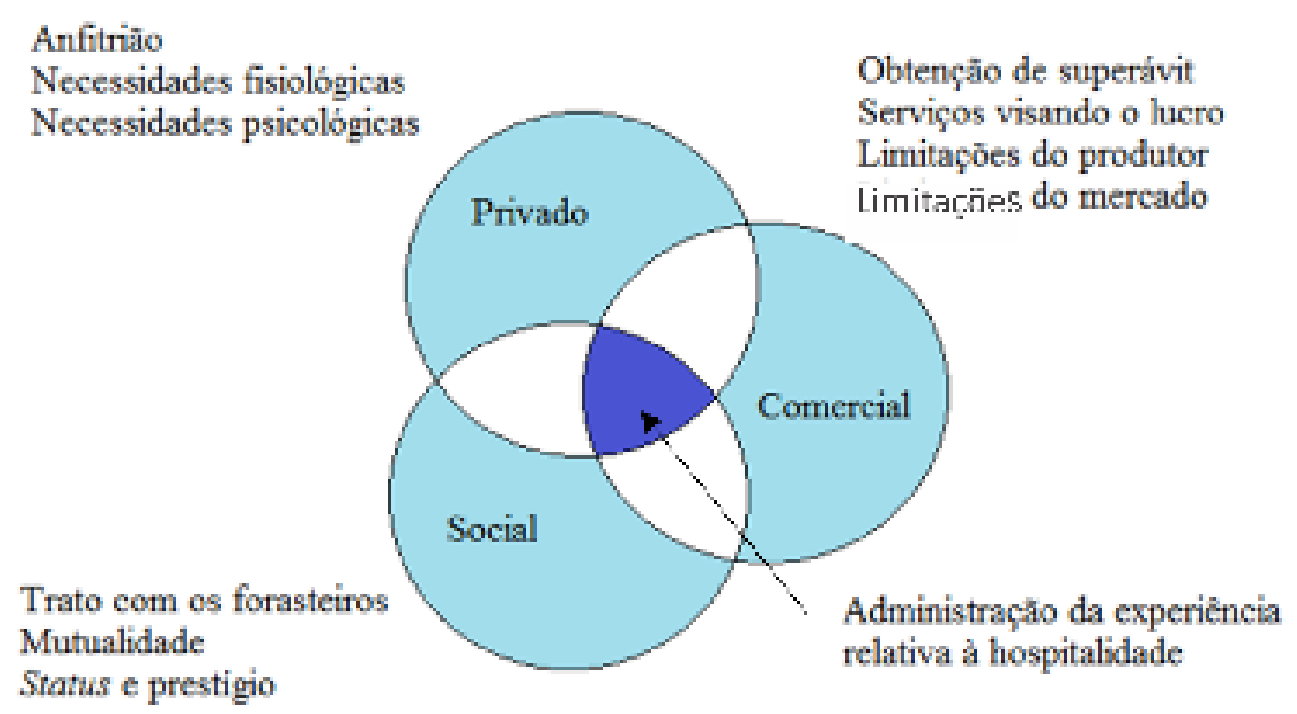

Fonte: C. Lashley, A. Morrison (Eds) (2000)

Dessa maneira, tratar de hospitalidade é trabalhar com relações humanas, que se baseiam em trocas humanas caracterizadas por diferentes formas de entrega (BROTHERTON; WOOD, 2000), que ultrapassam a relação em si, apontando para contextos de aceitação, inclusão do hóspede em espaços sociais sem limites, relações de afeição e simpatia, além dos aspectos emocionais envolvidos (Lashley, 2008).

Nesses três aspectos, Lashley (2008) postula sobre o encontro das necessidades psicológicas e fisiológicas presentes na hospitalidade privada, 
Rev.Tur., Visão e Ação, v21, n3, p309-335, Set./Dez. 2019 - Balneário Camboriú, Santa Catarina, Brasil

apontando questões relacionadas ao status e ao prestígio, o lidar com o estranho e a mutualidade das ações, características do domínio social. Além desses dois aspectos, o comercial define relações que são limitadas por contextos de mercado e de serviços. Muitas vezes, diferenças culturais e de origem são massificadas para que possa existir, principalmente no contexto comercial, um equilíbrio na relação. Bitner (1992) e Lugosi $(2008,2009)$ trataram algumas dessas dimensões relacionadas ao aspecto comercial. A essência da hospitalidade está diretamente relacionada à essência da experiência de consumo.

Para Verhoef et al. (2009), o conceito tem sido dominado pela perspectiva única do momento, esquecendo-se de que, de fato, são vários momentos, um continuum que alimenta a memória desde o primeiro contato, p.ex., da reserva da hospedagem, no caso da hotelaria, o momento do desfrute do serviço e o residual de percepção sobre a qualidade do que foi usufruído (Moretti, 2015; Knutson; Beck, 2004; Verhoef et al., 2009). Para Knutson e Beck, (2009), a questão prende-se na necessária participação das pessoas envolvidas e não apenas das coisas. Os autores ainda ampliam a discussão apontando para os três fatores que levam ao predomínio da experiência sobre outros aspectos do consumo: tecnologia, maior quantidade de consumidores e competição acirrada pela diferenciação e lealdade do consumidor. Sabe-se, todavia, que a hospitalidade no domínio comercial é um fato (MORETTI, 2015), notadamente em hotelaria, uma vez que a relação anfitrião-hóspede é mandatória. Mediante este ponto de tensão, Moretti (2015) percebeu que, embora ainda ocorram alguns debates sobre a possibilidade de haver ou não hospitalidade no domínio comercial, cada vez mais se estuda este domínio sob o ponto de vista dos conceitos de serviços.

Atualmente, caminha-se para o consenso de que o encontro é fonte de experiência por intermédio do ambiente físico (servicespace) e dos aspectos emocionais e sensoriais. $O$ aspecto relacional tende a ser percebido como o mais importante na avaliação dos clientes-hóspedes. As experiências de serviços são resultados da oferta equilibrada para o cliente/hóspede. Observa-se que os conceitos de hospitalidade são fundamentais para a busca da diferenciação, principalmente no atendimento, ou seja, nos primeiros serviços que são percebidos pelo hóspede, independente do segmento, de luxo ou não (MORETTI, 2015).

Portanto, a experiência de consumo caracteriza-se como um processo de relacionamento de longa duração, com possibilidades para as empresas atuarem em mais de um momento, operando espaços, elementos físicos, processos, tech points e touch points (pessoas).

Com base no exposto sobre Hospitalidade, pode-se apontar a Hipótese 1 do estudo: A hospitalidade influencia a satisfação dos usuários de hotéis de luxo.

\section{A HOSPITALIDADE E O ENCONTRO EM SERVIÇOS}

Assim como na tradição dos estudos de serviços, a hospitalidade, especificamente no domínio comercial, considera o encontro entre provedor- 
anfitrião e cliente-hóspede a essência da relação da entrega de serviços. As experiências prazerosas de consumo envolvidas nessa entrega de serviços constroem boas memórias. Elas criam no grupo de referência do consumidor uma troca de informações que gera uma imagem distinta para a marca e para o serviço em si (Shaw; Ivens, 2005). No entanto, como sustentam Gentile, Spiller e Noci (2007) e Verhoef et al. (2009), os diferentes níveis de relacionamento emocional, afetivo, espiritual, físico, sensorial, comportamental, intelectual, cognitivo, racional, relacional e social - são vivenciados em diversas formas e combinações, nem sempre envolvidas ao mesmo tempo em todos os tipos de experiência. Como advertem Gentile, Spiller e Noci (2007), são inúmeros os touch points de uma experiência, tanto quanto as respostas a eles pelos inúmeros clientes consumidores.

Neste sentido, a hospitalidade é mais do que o encontro em si, corroborada pela afirmação de Lashley, Lynch e Morrison (2007, p. 9) que, por meio de "uma abordagem mais abrangente da oferta de hospitalidade e atos hospitaleiros, organizações comerciais são mais capazes de reconhecer as experiências emocionais envolvidası. Walls et al. (2011) estudaram o papel fundamental das relações entre as interações humanas, os fatores situacionais, as características de cada indivíduo e as experiências em si, todos eles balizados pelas emoções e surpresas que cada momento proporciona ao consumidor, criando, finalmente, a identidade de cada um.

Conforme destaca Gross e Pullman (2012), os principais aspectos dos elementos que compõem uma experiência são: o relacional, ou seja, as interações estabelecidas em um contexto; e o físico, que ocorre durante o momento da experiência. $O$ aspecto relacional é o mais importante, uma vez que desempenha um papel crucial na avaliação dos clientes-consumidores.

Moretti (2015) afirma que "a dimensão emocional da hospitalidade faz com que os encontros nesta área sejam mais do que encontros de serviços comuns, os hóspedes avaliam a experiência total com base nos diversos touch points que ocorrem durante o encontro de serviços expandido".Dessa maneira, a relação anfitrião-hóspede incorpora outros elementos que são necessários para que o processo da entrega do serviço promova a experiência desejada pelo hóspede. Na hotelaria, a hospitalidade não se resume a uma boa recepção, a um bom atendimento do front, mas também à percepção da qualidade da infraestrutura e do conforto das instalações e todos os serviços consumidos, vivenciados e experimentados pelos clientes ao longo de sua estada.

O consumidor atual, especificamente deste mercado diferenciado de luxo, busca bens e serviços que se identificam com seu estilo de vida, que tragam experiências memoráveis e que tenham impacto sobre suas emoções. Nesse sentido, observa-se que o setor da hospitalidade tem se voltado para a criação dessas conexões emocionais com seus clientes, tentando influenciar a percepção do hóspede e criando experiências memoráveis e de grande prazer (SILVA; LEITE, 2010). 
Rev.Tur., Visão e Ação, v21, n3, p309-335, Set./Dez. 2019 - Balneário Camboriú, Santa Catarina, Brasil

\section{LUXO E HOTELARIA NO BRASIL}

O luxo é um conceito estudado por várias disciplinas como economia, marketing, história, sociologia e antropologia desde as sociedades pré-modernas. O luxo já foi sinônimo de dádiva e de cultura. Já foi símbolo de posição social e utilizado para fins religiosos ou profanos.

Em relação aos objetos de luxo, percebe-se que existe também uma hierarquia do consumo em relação a esses objetos, símbolos de uma tradição familiar ou de um contexto histórico, os quais se tornaram "códigos distintos de reconhecimento social" (Allérrès, 2006). Cada classe social escolhe os objetos que melhor representa sua classificação, desde os mais seletivos, raros e caros até os mais democratizados. O luxo encontra-se associado ao que é raro, sofisticado, com excelente qualidade e mais caro do que a média de produtos da mesma categoria.

Além disso, o luxo representa uma relação de pertencimento a uma determinada classe social, o que faz com seus integrantes se sintam prestigiados por participarem daquele nicho em questão. A motivação pela busca de pertencer a um grupo tão distinto pode ser intrínseca ou extrínseca (Shao \& Ross, 2019). Na perspectiva de Wiedmann, Hennigs e Siebels (2007), trata-se, por estes motivos, de uma elaboração social. Strehlau (2008) afirma que, apesar de a noção de luxo ser individual, podendo variar segundo as características pessoais até o limite de ser consumido na intimidade do lar, não se pode evitar a predominância do aspecto social como seu lado mais importante. Neste sentido, Galhanone (2013) ensina que o luxo se associa a um estilo de vida, valores estéticos, requinte e prestígio.

No entanto, Hemetsberger, Wallpach e Baver (2012) observam que o consumo no mercado de luxo não se relaciona mais com o fato de pertencer a determinada classe social, e sim com o fato de esse consumidor desejar experiências que definam a sua essência e o significado de seu prazer (Hemetsberger; Wallpach; Baver, 2012).

Além da necessidade desse nicho de mercado desejar experiências memoráveis que definam sua essência, segundo um estudo desenvolvido por Yang \& Mattila (2017), na hotelaria de luxo, algumas categorias de consumidores ("patricians" e "parvenus") demonstraram uma forte tendência de serem divulgadores dessas experiências pelo "Word-of-Mouth" (WOM). Os resultados indicaram que há uma forte intenção desses consumidores de divulgar boas experiências de serviços no mercado da hotelaria de luxo, mais do que em relação ao consumo de objetos de luxo. Dessa forma, fica um ponto de atenção aos gestores desses empreendimentos de luxo em relação a essa importante maneira de divulgação de seus serviços na sociedade. Os resultados dessa pesquisa indicam que os hotéis de luxo devem focar nos valores hedônicos de seus produtos e promover seus serviços como experiências memoráveis. Segundo Chang \& Ko (2017), a percepção de qualidade e de riscos pela perspectiva 
do hedonismo pode se tornar um fator crucial na decisão de recompra de um produto ou serviço no mercado de luxo.

No Brasil, o mercado de luxo apresentou um crescimento entre os anos de 2007 e 2011 de $R \$ 9,9$ bilhões para 20,9 bilhões, o que mostra seu potencial (Diniz, 2012). Dados levantados pela Associação Brasileira das Empresas de Luxo (Abrael) mostram que o segmento cresceu em 2016 de $11 \%$ a $13 \%$, devendose observar, principalmente, o mercado das regiões Centro-Oeste, Norte e Nordeste. O cenário aponta para que, mesmo com a recessão econômica, haja um crescimento e que o segmento avance rapidamente, em função do enorme potencial que o país apresenta. O site E-Commerce Brasil (2016), que analisa as tendências para o comércio, relacionou cinco atitudes e medidas que, nos próximos anos, a partir de 2017, poderão se tornar prática para o mercado de luxo.

A hotelaria de luxo também avançou nesse mercado e está relacionada à diferenciação, à ostentação e às experiências raras. No Brasil, a avaliação e a classificação hoteleira baseiam-se em dois importantes pilares: instalações e serviços. Essa combinação pode criar uma diferenciação importante no posicionamento de alguns hotéis. Destaca-se que este conceito de hotelaria de luxo é bastante recente, tendo em vista os estudos que já foram realizados sobre o tema (Felini, 2014). Assim, se for considerada a classificação do Ministério do Turismo, os hotéis são categorizados entre uma e cinco estrelas, com base em requisitos mandatórios e eletivos para as condições de infraestrutura, serviços e sustentabilidade. Isto é, os hotéis que são classificados com uma estrela atendem, basicamente, os parâmetros estabelecidos e os que recebem cinco estrelas atendem excedendo todos os requisitos.

A falta de uma categorização oficial de hotéis de luxo faz com que as classificações e as fontes de informações sejam muito restritas e, nem sempre, constantes e atualizadas. Agregam-se a esses parâmetros algumas categorias de associações que se estabeleceram no Brasil e no mundo com o propósito de diferenciar os estilos e os serviços hoteleiros.

O TripAdvisor publicou uma classificação, a partir da avaliação de seus usuários, dos 25 melhores hotéis de luxo no Brasil, o 2017 Traveller's Choice TripAdvisor. As primeiras dez escolhas dos usuários são pela ordem: 1) SaintAndrews - Gramado - RS; 2) Hilton Barra - Rio de Janeiro - RJ; 3) Kenoa Exclusive Beach Spa \& Resort - Barra de São Miguel - AL; 4) Belmond Hotel das Cataratas - Foz do IguaçU - PR; 5) Hotel Unique - São Paulo - SP; 6) Villas de Trancoso Hotel - Trancoso - BA; 7) Nomaa Hotel - Curitiba - PR; 8) Ponta dos Ganchos Exclusive Resort - Governador Celso Ramos - SC; 9) Nannai Resort \& Spa-Ipojuca-PE; 10) Hotel Fasano São Paulo - SP.

Pode ser observado que existe uma dificuldade muito grande em se estabelecer um parâmetro de classificação para hotelaria de luxo e, na ausência de uma classificação oficial para esse mercado, foi com base nas premissas e nos conceitos de hotel de luxo apresentados pela categorização da escolha dos 
Rev.Tur., Visão e Ação, v21, n3, p309-335, Set./Dez. 2019 - Balneário Camboriú, Santa Catarina, Brasil

usuários da TripAdvisor que se realizou a escolha dos equipamentos hoteleiros para aplicação da pesquisa de campo deste artigo, buscando diferenciais e experiências que atraíam os hóspedes desse nicho de mercado.

A influência da hospitalidade no encontro de serviços, em especial na hotelaria de luxo, indica as duas hipóteses restantes do estudo: Hipótese 2: A hospitalidade influencia o atendimento diferenciado nos hotéis de luxo; e Hipótese 3: $O$ atendimento diferenciado influencia a satisfação dos usuários de hotéis de luxo. O modelo testado é apresentado pela Figura 2. Nota-se que o constructo Hospitalidade influencia tanto a Satisfação quanto o Atendimento, tornando-se um antecedente deles. O constructo Satisfação é influenciado pelos outros dois constructos e, portanto, consequente deles. A amostra foi não probabilística, por conveniência (Costa, 2011). Trata-se de um modelo reflexivo, com o constructo Hospitalidade no papel de mediador entre os constructos Atendimento e Satisfação.

Figura 2 - Modelo da pesquisa

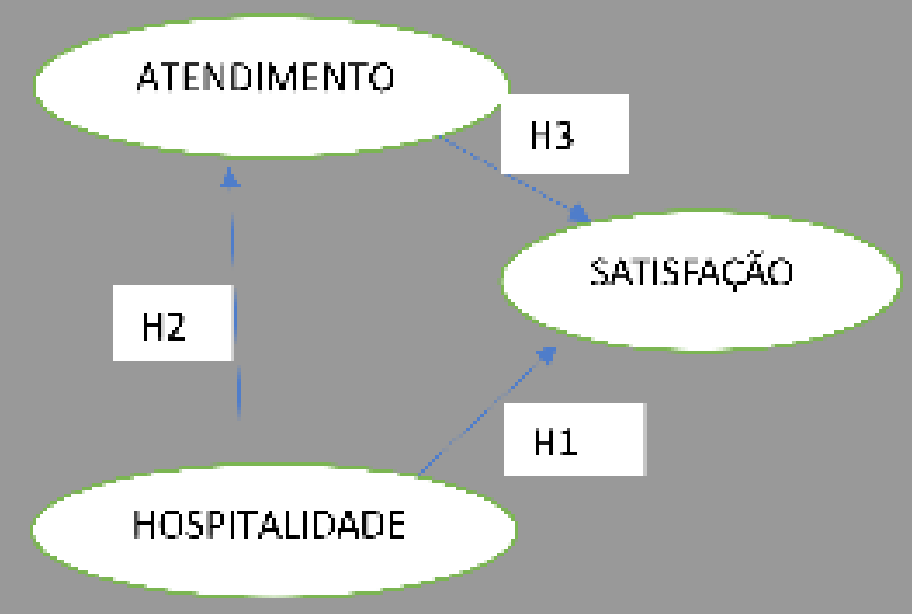

Fonte: Elaborada pelos autores

\section{METODOLOGIA}

A escolha do método misto se deu pela necessidade de, inicialmente, aprofundar o tema a partir de entrevistas com especialistas da área e colher informações sobre o atendimento a clientes de serviços de luxo (Malhotra, 2001; Cooper; Schindler, 2003).

\section{FASE QUALITATIVA}

Na fase qualitativa, por falta de uma classificação oficial para a categoria luxo na hotelaria e por se tratar de uma fase de construção dos construtos para a pesquisa, os objetos foram selecionados nos meios de hospedagem e restaurantes. 
O critério de escolha foi a expertise no mercado de luxo, a conveniência de acesso dos pesquisadores e a experiência daqueles profissionais no atendimento aos clientes. As entrevistas em profundidade foram realizadas por meio de um roteiro aberto e realizadas com três gerentes de meios de hospedagem e um restaurateur da cidade de São Paulo (SP). A construção do roteiro seguiu o procedimento padrão nestes casos, partindo de perguntas baseadas nas dimensões levantadas na literatura e explorando seus desdobramentos a partir das próprias respostas dos entrevistados (Sfeir, Silva, Garcia e Moretti, 2011).

As entrevistas foram gravadas e, posteriormente, transcritas para facilitar sua análise. Seguindo as recomendações de Bardin (2004), os conteúdos das entrevistas foram separados por temas que pudessem contribuir para a formação dos constructos a serem aplicados na fase quantitativa, privilegiando a técnica survey para aplicação nos usuários de hotéis de luxo.

Os resultados das entrevistas tiveram como foco mostrar as especificidades do mercado de luxo e como poderiam ser aplicadas para o caso dos hotéis de luxo. Foram selecionados quatro grupos com elementos que foram incluídos no instrumento da fase quantitativa: 1) perfil do consumidor de luxo e seus diferenciais, vivências e experiências anteriores, pois elas determinam as avaliações e os critérios dos clientes; 2) relacionamento com clientes de luxo, ficando evidenciado que o contato pessoal por parte de toda a equipe e busca de intimidade é fundamental; 3) comunicação com os clientes buscando o contato individualizado, prevalecendo a percepção de exclusividade do cliente; 4) diretrizes organizacionais para as equipes de atendimento, caracterizando o treinamento como uma importante ferramenta para que as equipes possam ter autonomia suficiente para buscar, entender e resolver uma necessidade desse perfil de consumidor.

\section{CONSTRUÇÃO DAS ESCALAS}

Estudos anteriores, como o de Silva (2016), serviram de orientação para a elaboração das questões envolvendo Hospitalidade, já que desenvolveram estudos neste sentido. Quanto ao instrumento de coleta para a etapa quantitativa desta pesquisa, optou-se por utilizar a escala tipo Likert de cinco pontos, variando desde 1 - Discordo totalmente, até 5 - Concordo totalmente.

\section{CONSTRUCTO HOSPITALIDADE}

Este constructo procura captar a impressão que os usuários de hotéis de luxo têm da sua estadia à luz de variáveis que foram exploradas sob o conceito de hospitalidade. O constructo Hospitalidade foi formado por oito variáveis selecionadas da literatura, conforme mostrado no Quadro 1: 
Rev.Tur., Visão e Ação, v21, n3, p309-335, Set./Dez. 2019 - Balneário Camboriú, Santa Catarina, Brasil

Quadro 1 - Constructo Hospitalidade

\begin{tabular}{|l|l|}
\hline $\begin{array}{l}\text { Os funcionários do hotel me recebiam com um sorriso a } \\
\text { qualquer momento. }\end{array}$ & Ariffin (2013) \\
\hline $\begin{array}{l}\text { Fui recebido de forma calorosa na chegada. } \\
\text { Neste hotel todos os hóspedes são tratados com o mesmo } \\
\text { valor, independente de suas características. }\end{array}$ & $\begin{array}{l}\text { Lashley (2008) } \\
\text { e Silva (2016) }\end{array}$ \\
\hline $\begin{array}{l}\text { Neste hotel, os hóspedes sentem-se protegidos em um } \\
\text { ambiente seguro. }\end{array}$ & $\begin{array}{l}\text { Lashley (2008) } \\
\text { e Silva (2016) }\end{array}$ \\
\hline $\begin{array}{l}\text { Os funcionários do hotel se empenharam para me } \\
\text { proporcionar uma experiência única e memorável. }\end{array}$ & $\begin{array}{l}\text { Lashley (2005) } \\
\text { e } \\
\text { Especialistas }\end{array}$ \\
\hline O hotel me proporcionou inesperados mimos e agrados. & $\begin{array}{l}\text { Hemmington } \\
\text { (2007) e } \\
\text { Especialistas }\end{array}$ \\
\hline $\begin{array}{l}\text { A hospitalidade pareceu ser uma atitude natural dos } \\
\text { funcionários do hotel, independentemente de qualquer } \\
\text { controle ou incentivos extras. }\end{array}$ & Ariffin (2013) \\
\hline $\begin{array}{l}\text { O hotel me proporcionou novas formas de relaxar, } \\
\text { contemplar e apreciar minha viagem. }\end{array}$ & Especialistas \\
\hline
\end{tabular}

Fonte: Elaborado pelos autores

\section{CONSTRUCTO ATENDIMENTO DIFERENCIADO}

Este constructo foi elaborado a partir da literatura analisada nos aspectos do mercado de luxo e dos resultados do pré-teste da pesquisa qualitativa. Ariffin (2013) também contribuiu com parte das variáveis. Embora o autor esteja vinculado à tradição da hospitalidade, ele, efetivamente, contribuiu para algumas escalas naquele constructo. Ele procura medir a satisfação dos usuários de hotéis de luxo relativa ao atendimento diferenciado que estes serviços prestam. O constructo Atendimento Diferenciado foi formado por oito variáveis, conforme demonstra o Quadro 2. 
Quadro 2 - Constructo Atendimento (Diferenciado)

\begin{tabular}{|l|l|}
\hline Os funcionários do hotel me trataram com muito respeito. & Ariffin (2013) \\
\hline $\begin{array}{l}\text { Os funcionários do hotel me ofereceram serviços impecáveis } \\
\text { desde a recepção, onde fui prontamente atendido. }\end{array}$ & Especialistas \\
\hline Os funcionários do hotel já sabiam meu nome. & Especialistas \\
\hline $\begin{array}{l}\text { Funcionários do hotel me acompanharam até meu quarto } \\
\text { após o check-in. }\end{array}$ & Ariffin (2013) \\
\hline Os funcionários do hotel estavam sempre prontos a ajudar. & Especialistas \\
\hline $\begin{array}{l}\text { Fiquei surpreso com o fato de os funcionários do hotel } \\
\text { conhecerem minhas preferências de passeios, comidas e } \\
\text { bebidas. }\end{array}$ & Especialistas \\
\hline $\begin{array}{l}\text { Os funcionários do hotel asseguraram que a acomodação } \\
\text { estivesse confortável para mim. }\end{array}$ & Ariffin (2013) \\
\hline Eu me senti em casa, enquanto estava hospedado no hotel. & Ariffin (2013) \\
\hline
\end{tabular}

Fonte: Elaborado pelos autores

\section{CONSTRUCTO SATISFAÇÃO}

Neste construto, foram utilizadas as escalas que Ariffin (2013) usou para medir a satisfação da sua amostra que, por sua vez, foi baseada na escala de four emotion-laden items (quatro itens carregados de emoção - em tradução livre) de Westbrook e Oliver's (1991). O primeiro item teve como base Olorunniwo, Hsu e Udo (2006). A sexta variável foi adaptada de Ariffin (2016). O objetivo, como o próprio nome do constructo indica, foi de capturar a emoção do usuário sobre sua estadia. O constructo Satisfação (dos usuários dos hotéis de luxo) foi formado por seis variáveis, conforme o Quadro 3.

Quadro 3 - Constructo Satisfação

\begin{tabular}{|l|l|}
\hline $\begin{array}{l}\text { Estou satisfeito com a minha decisão de hospedar neste } \\
\text { hotel. }\end{array}$ & Ariffin (2013) \\
\hline Minha decisão por este hotel foi acertada. & Ariffin (2013) \\
\hline Entendo que fiz a coisa certa ao escolher ficar neste hotel. & Ariffin (2013) \\
\hline $\begin{array}{l}\text { Acredito que minha experiência com este hotel foi } \\
\text { agradável. }\end{array}$ & Ariffin (2013) \\
\hline Eu recomendaria este hotel para outras pessoas. & Ariffin (2013) \\
\hline Os serviços deste hotel superaram minhas expectativas. & Ariffin (2016) \\
\hline
\end{tabular}

Fonte: Elaborado pelos autores 


\section{VALIDAÇÃO DAS ESCALAS}

Os procedimentos para validação das escalas testadas pelo instrumento de pesquisa seguiram as proposições de DeVellis (2003), Pasquali (2004) e Hair et al. (2009). Seguindo os passos desenvolvidos por Silva (2016), a elaboração ocorreu em quatro fases: a) identificação de escalas já testadas na literatura sobre o tema; b) validação de face, ou seja, adequação aos objetivos da pesquisa; c) validação semântica, ou adequação da linguagem aos padrões brasileiros; e d) validação estatística por meio do software SmartPLS.

Nas duas primeiras fases, o desenvolvimento feito por Silva (2016) tornouse a base da maioria das variáveis do constructo Hospitalidade, pois já estavam traduzidas e testadas. Nos demais constructos as escalas foram traduzidas do inglês por proficientes na língua e, posteriormente, novamente traduzidas para o ajuste de significado semântico e linguístico.

O procedimento de aprovação da escala foi realizado por intermédio de especialistas que serviram como juízes das variáveis propostas. O esquema utilizado nesta fase foi o snow ball (bola de neve). As escalas selecionadas foram enviadas para o juiz $n^{\circ} 1$ e, após analisadas, enviadas para os demais juízes da mesma maneira, até o juiz de $n^{\circ} 4$, quando a escala atingiu os objetivos propostos e foi transformada no instrumento para o survey (Pasquali, 2004). Suas sugestões foram incluídas na proposta conforme apresentada anteriormente. $\bigcirc$ instrumento foi pré-testado com um grupo de alunos de pós-graduação para verificar sua funcionalidade.

\section{PROCEDIMENTOS ANALÍTICOS PROPOSTOS}

Para avaliar a consistência da proposição, foi realizada uma Análise Fatorial Confirmatória por meio de uma Modelagem de Equações Estruturais Structural Equation Modeling - (SEM), pelo método dos Mínimos Quadrados Parciais - Partial Least Square (PLS), por meio do software SmarPLS 3, que permite a análise de dados não normalizados (Ringle; Wende; Becker, 2015). Silva (2016, p. 61) explica que é "uma técnica estatística multivariada que possibilita a avaliação simultânea de relações entre múltiplos constructos". Os indicadores de consistência são chamados de cargas fatoriais, obtidos nos relatórios do SmartPLS (Ringle, Silva, Bido, 2014; Gabriel, 2014; Silva, Moretti, Garcia, 2014).

Hair et al. (2012) e Ringle, Silva e Bido (2014) defendem que o SmartPLS permite avaliar relações causais entre constructos e fazer testes de hipóteses usando os coeficientes de caminho (Path Coefficients). Objetivando maior rigor, considerou-se o nível de significância (a) de $5 \%(0,05)$. 


\section{RESULTADOS DA PESQUISA}

\section{CaracterizaçÃo da Amostra}

Os dados foram coletados a partir de uma amostra de 462 hóspedes que compõem um mailing list com o cadastro de 7.000 usuários de hotéis, oriundos das mais diversas regiões do país. Consideraram-se para essa pesquisa os 25 hotéis de luxo classificados pelo TripAdvisor, por meio do 2017 Traveller's Choice TripAdvisor, tabela mencionada anteriormente neste artigo. O período da pesquisa de campo foi de 26/04/2017 a 08/05/2017. O questionário utilizado foi hospedado no site da Survey Monkey. Os usuários foram contatados via e-mail convidando-os a participarem da pesquisa, que procurou refletir a experiência de consumo na hotelaria de luxo. Eles responderam por meio do acesso ao link https://pt.surveymonkey.com/r/MV239DF.

A responsividade da amostra foi excelente, pois nos dois primeiros dias foram coletados $78,5 \%$ do total de respondentes. O link ainda ficou disponível por mais 15 dias, sendo registradas as demais respostas. Não foi necessária nenhuma comunicação de reforço e o resultado foi totalmente espontâneo.

Os resultados demográficos revelaram que $50 \%$ dos respondentes eram do sexo feminino, $81,3 \%$, com idade predominantemente acima de 41 anos e os demais, entre 21 e 40 anos. Outro dado revelado pelos respondentes foi o uso de hotéis da categoria luxo, tanto no Brasil como no exterior, com uma tendência maior de usuários no Brasil, 63,6\%.

A principal questão que se colocou na análise a seguir foi como analisar os coeficientes de caminho, que mostraram influência da Hospitalidade sobre o Atendimento e, consequentemente, sobre a Satisfação dos usuários de hotéis de luxo, apontadas nas hipóteses deste artigo.

Como mencionado anteriormente, os usuários do mercado de luxo são muito sensíveis ao tratamento individualizado e exclusivo, o que subsidia algumas das respostas que foram analisadas em relação aos constructos utilizados como balizadores dessa pesquisa.

\section{ANÁLISE FATORIAL CONFIRMATÓRIA}

Conforme explicado no item Procedimentos Analíticos, procedeu-se a uma Análise Fatorial Confirmatória por meio de Modelagem de Equações Estruturais. Para a validade convergente, buscou-se identificar cargas fatoriais superiores $(\lambda)$ a 0,60 entre os itens e o constructo mensurado e, para validade discriminante, exigiu-se que a raiz quadrada da Average Variance Extracted (AVE) do constructo fosse maior que a correlação deste com os outros constructos do modelo. Nesta fase, verificaram-se também a consistência interna da escala, por meio do Alpha de Cronbach (superior a 0,70), a confiabilidade composta (superior a 0,70) e a 
Rev.Tur., Visão e Ação, v21, n3, p309-335, Set./Dez. 2019 - Balneário Camboriú, Santa Catarina, Brasil

própria AVE (superior a 0,50), como recomendado pela literatura (Chin; Newsted, 1999; Hair et al., 2009; Levin; Fox, 2004). O modelo é apresentado na Figura 3 com as respectivas cargas fatoriais.

De acordo com vários pesquisados, pode-se dispor de diversos índices para avaliar o ajustamento do modelo ( Fornell; Larcker, 1981). Porém, não existe consenso sobre um único índice ou padrão. Portanto, múltiplos critérios devem ser empregados para avaliar, de modo geral, o ajustamento do modelo teórico (Bagozzi; Yi, 1988; Hair et al., 2009)

Figura 3 - Modelo com as respectivas cargas fatoriais

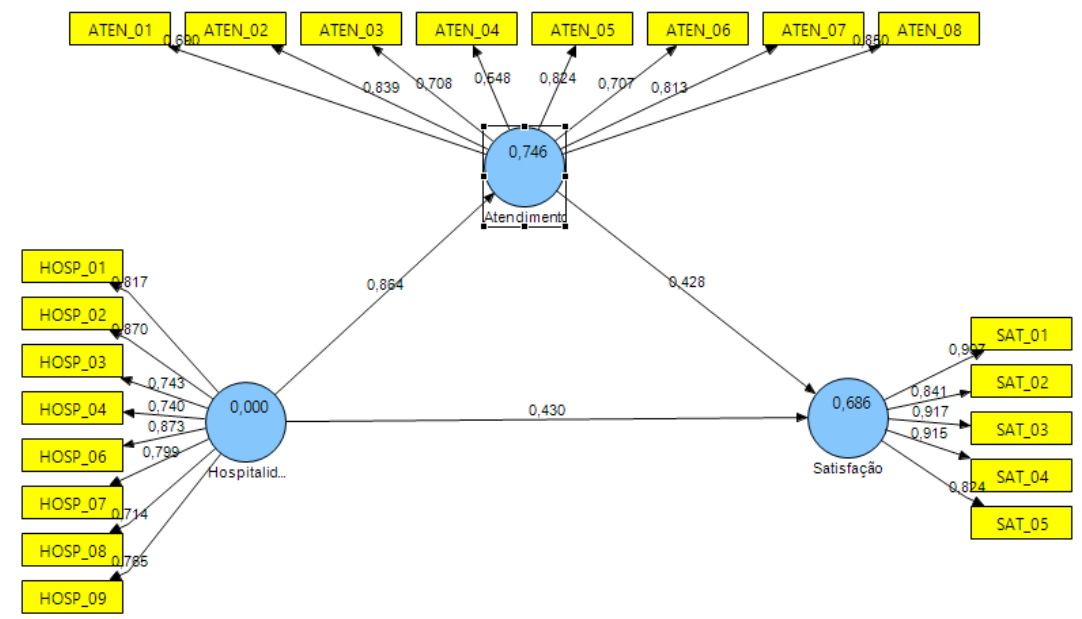

Fonte: Dados da pesquisa

A validade convergente foi observada pelas cargas apresentadas nos modelos PLS. No modelo, as cargas $\lambda$ variaram de 0,548 ( $\lambda$ ATEN_04) até 0,917 (XSAT_03). Do mesmo modo, a validade discriminante das variáveis latentes foi comprovada quando se verificou que as raízes quadradas de cada variável eram superiores à correlação entre elas e as demais variáveis latentes dos modelos, como demonstrado na Tabela 1.

Tabela 1 - Análise da validade discriminante do modelo

\begin{tabular}{|c|c|c|c|}
\hline Construtos & \multicolumn{1}{c|}{ Atendimento } & \multicolumn{1}{c|}{ Hospitalidade } & \multicolumn{1}{c|}{ Satisfação } \\
\hline Atendimento & $\mathbf{0 , 7 5 4}$ & & \\
Hospitalidade & 0,862 & $\mathbf{0 , 7 9 2}$ & \\
Satisfação & 0,799 & 0,799 & $\mathbf{0 , 8 8 2}$ \\
\hline
\end{tabular}

Fonte: Dados da pesquisa 
O indicador de ajuste do modelo foi satisfatório. Todas as AVEs foram superiores a 0,50 , a confiabilidade composta de todas as variáveis latentes foi superior a 0,6 e os coeficientes Alpha de Cronbach foram superiores a 0,70. Além disso, o indicador de ajustamento geral (GoF) foi superior a 0,36, podendo ser considerado como adequado. A Tabela 2 apresenta os indicadores identificados por constructo.

Tabela 2 - Índices de ajustamento do modelo

\begin{tabular}{|lcccc|}
\hline & \multicolumn{4}{c|}{ GoF $=\mathbf{0 , 6 8}$} \\
\hline Atendimento & AVE & C.C. & $\mathbf{R}^{2}$ & $\boldsymbol{\alpha}$ \\
Hospitalidade & 0,568 & 0,911 & 0,746 & 0,888 \\
Satisfação & 0,627 & 0,930 & & 0,914 \\
\hline
\end{tabular}

Nota: $a=$ Alfa de Cronbachs; C.C. $=$ Confiabilidade Composta

Fonte: Dados da pesquisa

A análise de regressão é usada como uma forma descritiva da análise de dados e utilizada para verificar a relação da variável dependente, neste caso, o constructo Satisfação com as variáveis independentes, isto é, com os constructos Hospitalidade e Atendimento diferenciado. Os coeficientes de regressão padronizados indicam o momento em que cada constructo afeta as variáveis latentes, quando estas aumentam de uma unidade. Na Figura 3, podem ser localizados os coeficientes de regressão associados a cada uma das variáveis observadas (Hospitalidade e Atendimento) e quanto elas impactam na variável latente Satisfação.

A variável Hospitalidade possui o maior coeficiente de regressão $(0,430)$ com a variável Satisfação, ou seja, quando esta aumenta de uma unidade, a maior contribuição para ela vem da Hospitalidade. A variável Atendimento obteve um índice muito próximo, 0,428. Finalmente, a variável Hospitalidade apresentou um coeficiente de regressão de 0,864 , mostrando sua influência sobre a variável Atendimento. 
Rev.Tur., Visão e Ação, v21, n3, p309-335, Set./Dez. 2019 - Balneário Camboriú, Santa Catarina, Brasil

Figura 4- Bootstrapping do modelo final

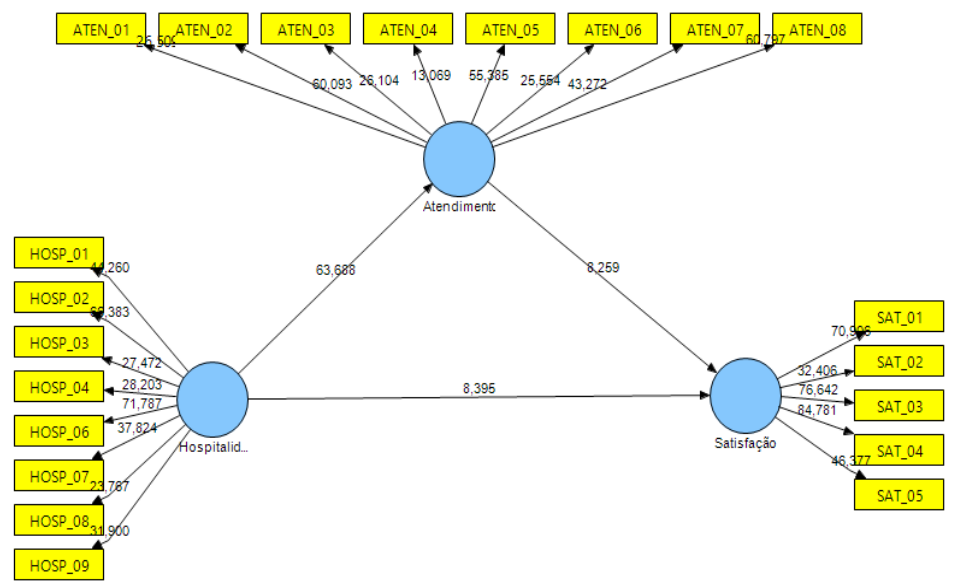

Fonte: Dados da pesquisa

Na Figura 4, também podem ser observados os valores dos coeficientes de determinação da variância $\left(R^{2}\right)$ da variável dependente Satisfação. Estes coeficientes, que estão no interior dos círculos que representam cada variável, indicam o percentual de variância da variável dependente que é explicado pelas variáveis independentes. No caso da variável Satisfação, o valor do coeficiente de determinação da variância $\left(R^{2}\right)$ obtido foi de $68,6 \%$ e no caso da variável Atendimento, o valor do coeficiente de determinação da variância obtido foi de $74,6 \%$.

Para a validação do modelo estrutural, foi utilizado o algoritmo de Bootstrapping (amostragem aleatória) do software SmartPLS 2.0M3 (Ringle; Wende; Will, 2015), com o parâmetro 5000 para o número de casos e amostras. Esse procedimento teve como objetivo realizar 5000 simulações com o conjunto de dados para a obtenção dos resultados do teste da distribuição † de Student. Os resultados do teste † dependem do número de questionários respondidos. Para uma amostra de 424 respondentes (graus de liberdade), o valor da distribuição t de Student é 1,98, para um intervalo de confiança de $95 \%$ e significância de 0,05 . O teste $\dagger$ de Student serve para testar a hipótese de que os coeficientes de correlação/regressão possam ser iguais a zero. Caso o resultado do teste $\dagger$ de Student seja igual ou superior a 2,00, a hipótese nula é rejeitada, ou seja, a correlação é significante.

A Tabela 3 mostra os resultados das análises conduzidas para testar as hipóteses apresentadas. 
Tabela 3 - Coeficientes dos caminhos do modelo testado

\begin{tabular}{|llcccc|}
\hline Hipóteses & Caminhos & $\beta$ & t & (Sig.) & Resultado \\
\hline H3 & Atendimento $\rightarrow$ Satisfação & 0,428 & 8,258 & $* * *$ & $\begin{array}{c}\text { Não } \\
\text { refutada } \\
\text { H1 }\end{array}$ \\
$\begin{array}{l}\text { Hospitalidade } \rightarrow \\
\text { Satisfação }\end{array}$ & 0,430 & 8,394 & $* * *$ & $\begin{array}{c}\text { Não } \\
\text { refutada }\end{array}$ \\
Hospitalidade & $\begin{array}{l}\text { Hõa } \\
\rightarrow \text { Atendimento }\end{array}$ & 0,864 & 63,687 & $* * *$ & $\begin{array}{c}\text { Não } \\
\text { refutada }\end{array}$ \\
\hline
\end{tabular}

Nota*: $p<0,05 ; * * p<0,01 ; * * * p<0,001$; n.s.= não significante

Fonte: Dados da pesquisa

Consumidores que experimentam altos níveis na qualidade do serviço oferecido tendem a repetir a experiência, tornando-se consumidores leais ao hotel que frequentam $(\beta=0,428, t=8,258, p<0,001)$. Esse achado vai ao encontro do que já foi discutido por outros pesquisadores tanto nas áreas de hospitalidade, hotelaria e marketing de serviços (Caruana, 2002).

Com relação à $\mathrm{H} 1$ - A hospitalidade influencia a satisfação dos usuários de hotéis de luxo, ela também não foi refutada, pois os coeficientes de caminho do modelo estrutural indicam que a Hospitalidade possui uma relação positiva e significante com a Satisfação $(\beta=0,430, t=8,394, p<0,001)$. Quanto à H2 - A hospitalidade influencia $O$ atendimento diferenciado nos hotéis de luxo, da mesma forma, foi demonstrado que existe uma relação positiva e significante entre a Hospitalidade e o Atendimento $(\beta=0,864, t=63,687, p<0,001)$, fazendo com que H3 também não fosse refutada.

No tocante às hipóteses 1 e 2 que se relacionam à Hospitalidade, podese destacar que resultados semelhantes ocorreram em estudos nacionais que procuraram estudar esse aspecto no contexto a partir de diferentes relações. Podem-se destacar sete estudos: Silva (2016), diretrizes organizacionais e atendimento; Pinotti (2016), meios de hospedagem alternativos; Cruz (2017), ferramentas de compra on-line; Crotti (2017), hotéis de luxo; Quitéria (2017), hospitalidade virtual em sites de compras on-line; Polazzo (2018), para o Airbnb; e Oliveira (2018), em instituições de ensino superior. Os resultados mostraram que os públicos envolvidos confundem hospitalidade e atendimento.

A H3 - O atendimento diferenciado influencia a satisfação dos usuários de hotéis de luxo - não foi refutada, pois os coeficientes dos caminhos do modelo estrutural indicam que Atendimento possui uma relação positiva e significante com a Satisfação.

Os resultados mais uma vez vão ao encontro de importantes estudos que buscaram medir a influência da hospitalidade na oferta de serviços, como o pioneiro Tepeci e Barttlet (2002), Teng (2011), Dawson, Abbott e Shoemaker (2011), Dawson e Abbott (2011), Ariffin e Maghzi, (2012), Ariffin (2013), Ariffin, Nameghi 
Rev.Tur., Visão e Ação, v21, n3, p309-335, Set./Dez. 2019 - Balneário Camboriú, Santa Catarina, Brasil

e Zakaria (2013). Esses trabalhos demonstraram que a hospitalidade pode ser percebida como fator crucial para a criação de uma experiência positiva para empresas de serviços, aproximando-se dos critérios adotados deste campo específico (Blain \& Lashley, 2014; Tasci \& Semrad, 2016).

Embora a análise estatística seja exaustiva, a opção de se usar a Modelagem de Equações Estruturais (MEE) é necessária para mostrar se o modelo testado é ajustado e equilibrado, o que foi comprovado pelos indicadores apurados. Enquanto a análise descritiva mostrou a avaliação de cada uma das questões pela amostra, a MEE mostrou como elas se relacionam entre si, além de realizar o teste das hipóteses.

As cargas fatoriais foram bastante elevadas, a Confiabilidade Composta mostrou altos índices de ajuste, além do GoF ter-se mostrado igualmente alto. Pode-se afirmar, portanto, que a Satisfação é explicada pela Hospitalidade e o Atendimento para o caso dos hotéis de luxo, tornando-se duas opções cruciais para se obter boa avaliação dos seus usuários.

\section{CONSIDERAÇÕES FINAIS}

Este trabalho buscou entender como a relação de prestação de serviço em um mercado tão distinto como o de hospedagem de luxo pode ser ainda mais potencializada pela qualidade e pela diferenciação no atendimento, para que seus consumidores tenham suas expectativas atendidas e, até mesmo, superadas, criando uma relação de confiança e satisfação.

Buscaram-se na Hospitalidade os conceitos e os aspectos do acolhimento, relacionando-os aos elementos presentes no processo de atendimento dos hóspedes em hotéis de luxo. E, finalmente, tentou-se evidenciar a satisfação dos hóspedes em relação aos serviços prestados, em especial pelas equipes de front.

Diretrizes e valores organizacionais são fundamentais para inspirar atitudes e nortear ações dos funcionários de um empreendimento hoteleiro de luxo. Esses valores devem levar em conta o conhecimento das características e o perfil dos seus usuários e, consequentemente, influenciar o atendimento diferenciado ao hóspede. Pode-se pensar na geração de uma cultura organizacional, por meio de diretrizes, normas e valores, que poderão ser disseminados por toda a organização, inspirando todos os níveis da organização.

No entanto, parece ser fundamental que a autenticidade e o aspecto genuíno nas relações no mercado de luxo sejam parte dos valores essenciais da organização. A percepção do usuário do mercado de luxo ocorre logo no primeiro contato. As equipes de atendimento precisam estar cientes da importância de suas ações nesse encontro. Por muitas vezes, a falta de um contato individualizado, seja por se direcionar ao hóspede chamando-o pelo nome, ou mesmo por conhecer e mencionar um desejo que ele tenha expressado em algum momento, pode fazer toda a diferença. 
O fator emocional de percepção de acolhimento não se mostrou presente em algumas das repostas da pesquisa. Esse elemento deve receber especial atenção pela gestão dos hotéis por ter se mostrado significativo para os usuários da hotelaria de luxo. Deve-se considerar que a avaliação dos serviços será sempre a partir da perspectiva dos propósitos dos indivíduos que participam dessa díade na relação comercial.

Por fim, a satisfação dos usuários do mercado de hotelaria de luxo mostrou-se evidenciada na necessidade de terem algumas de suas expectativas atendidas, como o caso de segurança, cordialidade e simpatia e algumas até mesmo superadas. A criação de um vínculo mais próximo e íntimo nessa relação, perpetuando-a de alguma maneira, é um elemento de forte significado para esse perfil de consumidor.

Com o intuito de responder à problemática apresentada nessa pesquisa, evidenciou-se a relação entre a Hospitalidade, o Atendimento Diferenciado e a Satisfação dos Usuários da Hotelaria de Luxo apresentada pelas hipóteses deste trabalho. Por intermédio da aplicação dos questionários e do teste de escala, foi possível obter informações que sustentaram a argumentação que colaborou para a compreensão dessas relações.

Como foi possível perceber, os respondentes indicaram que parece ser possível reconhecer a presença da hospitalidade em sua perspectiva de acolhimento, presente no atendimento e que, quanto maior a presença desses conceitos no momento da interação, melhor é a avaliação do serviço e maior a identificação do usuário com o hotel. A principal contribuição teórica da pesquisa foi comprovar a validade do modelo alcançando-se evidências satisfatórias para a maioria das questões do instrumento utilizado na coleta de dados que mediu o que se propôs a medir. Como apresentado na discussão dos resultados, os coeficientes de confiabilidade interna apresentaram valores dentro dos padrões aceitáveis e as hipóteses foram comprovadas.

Para a teoria, o resultado mostra que é possível se obter informações sobre a satisfação dos hóspedes por meio de instrumentos quantitativos. A utilização de constructos com base na teoria existente revelou-se muito útil para a ampliação dos conhecimentos neste campo.

A contribuição gerencial correspondeu ao objetivo da pesquisa, cujo objetivo explicitado no início era buscar evidências das variáveis envolvidas no atendimento do hóspede em hotéis de luxo no Brasil. Os resultados evidenciaram que o diferencial do serviço para usuários de mercado de luxo está além de oferecer mimos e agrados. A pesquisa revelou que esta prática, muito usual na hotelaria, deve ser cuidadosamente avaliada, uma vez que as expectativas e os desejos dos hóspedes estão muito além dessa característica da excelência de atendimento. A gestão da hotelaria deve dedicar uma atenção especial a essa mudança, que leva em consideração detalhes que mostram que cada usuário é exclusivo e único. 
O atendimento diferenciado mostrou-se superior à distribuição de mimos e agrados, assim como a cordialidade, a simpatia e o conhecimento das preferências individuais se mostraram fatores importantes para a percepção de qualidade do serviço. O momento do encontro no setor de serviços, principalmente o hoteleiro de luxo, mostrou-se como o fator fundamental que se deve colocar atenção nesta área, constituindo-se de uma contribuição tanto para a academia como para o campo gerencial.

As limitações da pesquisa caracterizam-se pela amostra que, embora satisfatória para comprovar o modelo e o instrumento, ainda não representa um volume suficiente para que seja possível universalizar os resultados. Contudo, as evidências obtidas podem se tornar um importante instrumento para os campos acadêmico e gerencial, contribuindo assim para o estudo da experiência de consumo na hotelaria de luxo no Brasil. E, com base neste propósito, averiguar o nível de hospitalidade percebido pelos usuários dos hotéis de luxo e sua satisfação em relação aos conceitos da hospitalidade e do atendimento em relação aos serviços diferenciados apresentados, além da experiência do hóspede como única e distinta.

\section{REFERÊNCIAS}

Allérès, D. (2006). Estratégias de Marketing. Rio de Janeiro: FGV.

Anderson, J. C., \& Gerbing, D. W. (1988). Structural equation modeling in practice: A review and recommended two-step approach. Psychological bulletin, 103(3), 411.

Ariffin, A.A.M. \& Maghzi, A.A. (2012). A preliminary study on customer expectations of hotel hospitality: influences of personal and hotel factors. International Journal of Hospitality Management, 31, 191-198.

Ariffin, A. A. M., Nameghi, E. N., \& Zakaria, N. I. (2013). The effect of hospitableness and servicescape on guest satisfaction in the hotel industry. Canadian Journal of Administrative Sciences/Revue Canadienne des Sciences de l'Administration, 30(2), 127-137.

Ariffin, A. A. M. (2013). Generic dimensionality of hospitality in the hotel industry: A hostguest relationship perspective. International Journal of Hospitality Management, 35 , 171-179.

Ariffin, A. A. M., \& Omar, N. B. (2016). Surprise, hospitality, and customer delight in the context of hotel services. In Tourism and Hospitality Management (pp. 127-142). Emerald Group Publishing Limited.

Bagozzi, R. P., \& Yi, Y. (1988). On the evaluation of structural equation models. Journal of the academy of marketing science, 16(1), 74-94.

Bardin, L. (2004). Análise de conteúdo. 3a. Lisboa: Edições, 70.

Bitner, M. J. (1992). Servicescapes: The impact of physical surroundings on customers and employees. The Journal of Marketing, 57-71. 
Blain, M. \& Lashley, C. (2014). Hospitableness: the new service metaphor? Developing an instrument for measuring hosting. Research in Hospitality Management, $(1,2), 1-8$

Brasil. Ministério do Turismo. Sistema brasileiro de classificação de meios de hospedagem. 2016. Disponível em: < http://www.classificacao.turismo.gov.br/MTURclassificacao/ mtur-site >. Acesso em: 30 out, 1916.

Brotherton, B., \& Wood, R. (2000). Hospitality and hospitality management. In search of hospitality: Theoretical perspectives and debates, 134-156.

Camargo, L. O. L. (2015). Os interstícios da hospitalidade. Revista Hospitalidade, 42-69.

Campanário, P. M et al. Valor percebido do luxo: uma comparação entre Austrália e Brasil. 2014. 193 f. Dissertação (Mestrado em Administração) - Programa de pósGraduação em Administração, Universidade Nove de Julho, São Paulo, 2014.

Campbell, C. (2001). A ética romântica e o espírito do consumismo moderno. Rocco.

Caruana, A. (2002). Service loyalty: The effects of service quality and the mediating role of customer satisfaction. European journal of marketing, 36(7/8), 811-828.

Chang, Y., \& Ko, Y. J. (2017). Consumers' perceived post purchase risk in luxury services. International Journal of Hospitality Management, 61, 94-106.

Chin, W. W., \& Newsted, P. R. (1999). Structural equation modeling analysis with small samples using partial least squares. Statistical strategies for small sample research, 1(1), 307-341.

Cooper, D., \& Schindler, P. (2003). Métodos de Pesquisa em Administração Métodos de Pesquisa em Administração Métodos de Pesquisa em Administração.

Costa, F. D. (2011). Mensuração e desenvolvimento de escalas: aplicações em administração. Rio de Janeiro: Ciência Moderna.

D'Angelo, A. C. (2004). Valores e significados do consumo de produtos de luxo.

Dawson, M., Abbott, J., \& Shoemaker, S. (2011). The Hospitality Culture Scale: A measure organizational culture and personal attributes. International Journal of Hospitality Management, 30, 290-300.

Dawson, M., \& Abbott, J. (2011). Hospitality culture and climate: A proposed model for retaining employees and creating competitive advantage. International Journal of Hospitality \& Tourism Administration, 12 (4), 289-304.

DeVellis, R. F. (2003). Scale development: Theory and applications. Sage publications.

Dhir, L. A. The Ultimate luxury hoteliering 101! Part 1. International Hospitality Management, 2016a. Disponível em: <http://www.hospitalitynet.org/news/4077253.html>. Acesso em: 2 set. 2016.

Dhir, L. A. The Ultimate luxury hoteliering 101! Part 2. International Hospitality Management, 2016b. Disponível em: < http://www.hospitalitynet.org/news/4077254.html>. Acesso em: 2 set. 2016. 
Rev.Tur., Visão e Ação, v21, n3, p309-335, Set./Dez. 2019 - Balneário Camboriú, Santa Catarina, Brasil

Diniz, C. (2012). O Mercado do Luxo No Brasil: tendências e oportunidades. Editora Seoman.

E-Commerce Brasil. Quais são as cinco tendências para o comércio de luxo no Brasil? 2016. Disponível em: <https://www.ecommercebrasil.com.br/noticias/cincotendenciasmercado-de-luxo/>. Acesso em: 20 out. 2016.

FecomercioSP. Mercado de luxo cresce mesmo com a crise. 2016. Disponível em <http:// www.fecomercio.com.br/noticia/mercado-de-luxo-cresce-mesmo-com-a-crise>. Acesso em: 11. jun. 2008.

Felini, A. (2014). Análise dos fatores intrínsecos do marketing de destino que potencializam o segmento do turismo de luxo em Balneário Camboriú - SC. 2014. 127 f. Dissertação (Mestrado em Turismo e Hotelaria) - Programa de Pós-Graduação em Turismo e Hotelaria, Universidade do Vale do Itajaí, Balneário Camboriú-SC, 2014. Disponível em: < http://siaibib01.univali.br/pdf/Alessandra\%20Felini.pdf >

Ferreira, H., \& Teixeira, A. A. (2013). 'Welcome to the experience economy': assessing the influence of customer experience literature through bibliometric analysis (No. 481). Universidade do Porto, Faculdade de Economia do Porto.

Fornell, C., \& Larcker, D. F. (1981). Evaluating structural equation models with unobservable variables and measurement error. Journal of marketing research, 39-50.

Frasson, M. S. (2014). Os sentimentos como consequência da experiência do consumo de luxo.

Gabriel, M. L. (2014). Métodos Quantitativos em Ciências Sociais. Sugestões para Elaboração do Relatório de Pesquisa. Desenvolvimento em Questão, 12 (28).

Galhanone, R.F. (2013).Valor percebido pelo consumidor de produtos de luxo: proposição de um modelo teórico (Doctoral dissertation, Universidade de São Paulo).

Gentile, C., Spiller, N., \& Noci, G. (2007). How to sustain the customer experience: An overview of experience components that co-create value with the customer. European Management Journal, 25(5), 395-410.

Gross, M. A., \& Pullman, M. (2012). Playing their roles: Experiential design concepts applied in complex services. Journal of Management Inquiry, 21 (1), 43-59.

Gurzki, H., \& Woisetschläger, D. M. (2017). Mapping the luxury research landscape: A bibliometric citation analysis. Jounal of Business Research, 77, 147-166

Hair, J. F., Black, W. C., Babin, B. J., Anderson, R. E., \& Tatham, R. L. (2009). Análise multivariada de dados. Bookman editora

Hair, J. F., Sarstedt, M., Ringle, C. M., \& Mena, J. A. (2012). An assessment of the use of partial least squares structural equation modeling in marketing research. Journal of the academy of marketing science, 40(3), 414-433.

Hemetsberger, A., von Wallpach, S., \& Baver, M. (2012). Because I'm Worth It-Luxury and the Construction of Consumers' Selves. ACR North American Advances. 
Hemmington, N. (2007). From service to experience: Understanding and defining the hospitality business. The Service Industries Journal, 27(6), 747-755.

Keating, M., \& Harrington, D. (2003). The challenges of implementing quality in the Irish hotel industry. Journal of European Industrial Training, 27(9), 441-453.

Knutson, B. J., \& Beck, J. A. (2004). Identifying the dimensions of the experience construct: development of the model. Journal of Quality Assurance in Hospitality \& Tourism, 4 (34), 23-35.

Knutson, B. J., Beck, J. A., Kim, S., \& Cha, J. (2009). Identifying the dimensions of the guest's hotel experience. Cornell Hospitality Quarterly, 50(1), 44-55.

Lai, I. K. W., \& Hitchcock, M. (2017). Sources of satisfaction with luxury hotels for new, repeat, and frequent travelers: A PLS impact-asymmetry analysis. Tourism Management, 60, 107-129.

Lashley, C. (2000). Towards a theoretical. In search of hospitality: Theoretical perspectives and debates, 1.

Lashley, C. (2008). Studying hospitality: insights from social sciences. Scandinavian Journal of Hospitality and Tourism, 8(1), 69-84.

Lashley, C., Lynch, P., \& Morrison, A. J. (Eds.). (2007). Hospitality: A social lens. Elsevier.

Lashley, C., Morrison, A., \& Randall, S. (2005). More than a service encounter? Insights into the emotions of hospitality through special meal occasions. 12(1), 80-92.

Levin, J., \& Fox, J. A. (2004). Estatística para ciências humanas. In Estatística para ciências humanas. Pearson.

Lugosi, P. (2008). Hospitality spaces, hospitable moments: Consumer encounters and

Affective experiences in commercial settings. Journal of Foodservice, 19(2), 139-149.

Lugosi, P. (2009). The production of hospitable space: Commercial propositions and consumer co-creation in a bar operation. Space and Culture, 12 (4), 396-411.

Malhotra, N. K. (2001). Montingelli Jr Nivaldo; Farias, A. A. (Trad.). Pesquisa de marketing: Uma orientação aplicada.

Mohsin, A., \& Lockyer, T. (2010). Customer perceptions of service quality in luxury hotels in New Delhi, India: an exploratory study. International Journal of Contemporary Hospitality Management, 22 (2), 160-173.

Montandon, A. (201 1). O livro da Hospitalidade: acolhida do estrangeiro na história e nas culturas. São Paulo: SENAC.

Moretti, S. L. A. (2015). Encontros de hospitalidade, experiência de consumo e relacionamento com clientes: proposta preliminar para sua integração. Anais... Seminário da Associação Nacional de Pesquisa e Pós-Graduação em Turismo, Natal-RN, Brasil. 
Rev.Tur., Visão e Ação, v21, n3, p309-335, Set./Dez. 2019 - Balneário Camboriú, Santa Catarina, Brasil

Olorunniwo, F., Hsu, M. K., \& Udo, G. J. (2006). Service quality, customer satisfaction, and behavioral intentions in the service factory. Journal of services marketing, 20(1), 5972.

O'Sullivan, E. L., \& Spangler, K. J. (1998). Experience marketing: strategies for the new Millennium. Venture Publishing Inc.

Pasquali, L. (2004). Análise fatorial para pesquisadores. Petrópolis: Vozes

Phau, I., \& Prendergast, G. (2000). Consuming luxury brands: the relevance of the 'rarity principle'. The Journal of Brand Management, 8(2), 122-138.

Pitt-Rivers, J. (2012). The law of hospitality. HAU: Journal of Ethnographic Theory, 2(1), 501 517.

Ringle, C. M., Da Silva, D., \& Bido, D. D. S. (2014). Modelagem de equações estruturais com utilização do SmartPLS. REMark, 13(2), 54.

Ringle, C. M., Wende, S., \& Becker, J. M. (2015). SmartPLS 3. Boenningstedt: SmartPLS GmbH, http://www. smartpls.com.

Sfeir, S. A., da Silva, D., Neves Garcia, M., \& do Amaral Moretti, S. L. (2011). Estratégias empresariais para medicamentos genéricos no brasil: um estudo com as dez maiores empresas do setor. Revista Ibero Americana de Estratégia, 10(1).

Shao, W., Grace, D., \& Ross, M. (2019). Consumer motivation and luxury consumption: Testing moderating effects. Journal of Retailing and Consumer Services, 46, 33-44.

Shaw, C., \& Ivens, J. (2005). Building great customer experiences. Basingstoke: Palgrave Macmillan.

Silva, C. C. B. D. (2016). As relações entre hospitalidade, diretrizes organizacionais e atendimento ao hóspede na hotelaria: um estudo com modelagem de equações estruturais.

Silva, J. P. D., \& Leit, Y. V. P. (2010). Hospitalidad y ambiente en los hoteles: Su influencia en el comportamiento del consumo. Estudios y perspectivas en turismo, 19(3), 330345.

Souza, C. C. M., da Silva, D., do Amaral Moretti, S. L., \& Garcia, M. N. (2014). Construção e validação de escala de qualidade de ensino e serviços: um estudo com alunos de cursos de graduação em administração de empresas. REGE-Revista de Gestão, $21(1), 65-82$.

Strehlau, S. (2008). Marketing do luxo. São Paulo: Cengage Learning.

Tasci, A. D., \& Semrad, K. J. (2016). Developing a scale of hospitableness: A tale of two worlds. International Journal of Hospitality Management, 53, 30-41.

Teng, C.C. (2011). Commercial hospitality in restaurants and tourist accommodation: Perspectives from international consumer experience in Scotland. International Journal of Hospitality Management, 30, 866-874. 
Tepeci, M., \& Bartlett, A. B. (2002). The hospitality industry culture profile: a measure of individual values, organizational culture, and person-organization fit as predictors of job satisfaction and behavioral intentions. International Journal of Hospitality Management, 21 (2), 151-170.

Verhoef, P. C., Lemon, K. N., Parasuraman, A., Roggeveen, A., Tsiros, M., \& Schlesinger, L. A. (2009). Customer experience creation: Determinants, dynamics and management strategies. Journal of retailing, 85(1), 31-41.

Walls, A., Okumus, F., Wang, Y., \& Kwun, D. J. W. (2011). Understanding the consumer experience: An exploratory study of luxury hotels. Journal of Hospitality Marketing \& Management, 20(2), 166-197.

Westbrook, R. A., \& Oliver, R. L. (1991). The dimensionality of consumption emotion patterns and consumer satisfaction. Journal of consumer research, 18(1), 84-91.

Wiedmann, K. P., Hennigs, N., \& Siebels, A. (2007). Measuring consumers' luxury value perception: a cross-cultural framework. Academy of Marketing Science Review, 2007, 1.

Yang,W. \& Mattila, A.S. (2017). The impact on status seeking on consumers' word of mouth and product preference - A comparison between luxury hospitality services and luxury goods. Journal of Hospitality \& Tourism Research, 41 (1), 3-22.

\section{Contribuição de cada autor na construção do artigo:}

Maria Stela Reis Crotti: Pesquisa, elaboração da fundamentação teórica, procedimentos metodológicos e análise dos resultados

Sérgio Luiz do Amaral Moretti: Orientação e participação na teoria, procedimentos metodológicos e análise dos resultados 